CASE REPORT

\section{Ipilimumab Causing Autoimmune Hypophysitis : A Case Report}

\section{Maria Jose Velasco Acuna" and Kamal Shoukri ${ }^{2}$}

${ }^{1}$ Department of Endocrinology and Metabolism, University of Connecticut School of Medicine, Farmington, CT, USA

${ }^{2}$ Department of Endocrinology, Saint Francis Hospital, Hartford, CT, USA

\begin{abstract}
Ipilimumab is a monoclonal antibody that down regulates cytotoxic T-lymphocyteassociated antigen 4, this in turn inhibits tumor progression by enhancing immunemediated destruction of malignant cells. It has shown promising outcomes in the treatment of various solid tumors and was approved by FDA in 2011 for treatment of melanoma. Side effects are relatively common and predominantly involve the gastrointestinal track, the neurological system as well the endocrine system, and are felt to be secondary to $T$ cell activation and proliferation.

Autoimmune hypophysitis causing anterior hypopituitarism has been described recently. Herein, we present a case of ipilimumab-induced hypophysitis in a 60-year-old male presenting with fatigue, headaches and nausea.
\end{abstract}

\section{Keywords}

Ipilimumab, hypophysitis, lymph node dissection

\section{Case Report}

Open Access

Citation: Velasco, MJ \& Shoukri K. Ipilimumab causing autoimmune hypophysitis: A Case Report. Endocrinology, Diabetes and Obesity. 2018; 1(1):1.

Received: Mar 18th, 2018 Accepted: May 03rd, 2018 Published: May 13th, 2018

Copyright: ๑ 2018 Velasco, MJ \& Shoukri K This is an open access article distributed under the terms of the Creative Commons Attribution License, which permits unrestricted use, distribution, and reproduction in any medium, provided the original author and source are credited.

Corresponding author:

Maria Jose Velasco Acuna, MD, Department of Endocrinology and Metabolism, University of Connecticut School of Medicine, Farmington, CT, USA. E-mail: ma_jose_velasco@hotmail.com
The patient is a 60 years-old Caucasian male with stage IIIc T4bN2bM0 melanoma of the right shoulder. He underwent excision with negative margins and lymph node dissection. He was enrolled in a clinical trial with Ipilimumab as monotherapy at a dose of $10 \mathrm{mg} / \mathrm{kg}$, administered 3-4 weeks apart up to four doses. Thyroid function test was normal: TSH 4.19 $\mathrm{ulU} / \mathrm{mL}(0.35-5.50)$ prior to initiation of therapy. Following the third dose, he reported extreme fatigue, headaches, dizziness, nausea, anorexia and blurry vision. Biochemical findings confirmed central hypocortisolism, central hypothyroidism hyponatremia and central hypogonadism with the following values: ACTH $5.9 \mathrm{pg} / \mathrm{mL}$, aldosterone $4.3 \mathrm{ng} / \mathrm{dL}(<21)$, free cortisol $<0.03 \mathrm{mcg} / \mathrm{dL}(0.07-0.93), \mathrm{TSH} 0.1 \mathrm{ulU} / \mathrm{mL}(0.35-5.50)$, FT4 $0.5 \mathrm{ng} / \mathrm{dL}(0.5-1.3)$, FSH $2.4 \mathrm{mlU} / \mathrm{mL}$, LH $1.2 \mathrm{mIU} / \mathrm{mL}$, total testosterone $<7 \mathrm{ng} / \mathrm{dL}$, free testosterone non-detectable, bioavailable testosterone $<0.9 \mathrm{ng} / \mathrm{dL}$ and sodium of $124 \mathrm{mmol} / \mathrm{L}$.

MRI of the brain revealed no metastatic disease, the pituitary gland measured $8.5 \mathrm{~mm}$ with stalk thickness of $3.12 \mathrm{~mm}$ (Figure 1). He had no evidence of diabetes insipidus. He received $100 \mathrm{mg}$ of hydrocortisone three times a day for 24 hours and then transitioned to $40 \mathrm{mg}$ of prednisone as well as $50 \mathrm{mcg}$ of levothyroxine daily. His symptoms improved dramatically after steroids along with correction of hyponatremia and he was discharged on $40 \mathrm{mg}$ of prednisone and $50 \mathrm{mcg}$ of levothyroxine daily. Follow up a week later showed a FT4 of 0.8 $\mathrm{ng} / \mathrm{dL}$ and normal electrolytes. He was advised to decrease prednisone to $30 \mathrm{mg}$ a day and increase levothyroxine to $75 \mathrm{mcg}$ a day. His symptoms resolved on follow up visit. 
Figure 1. MRI Scan
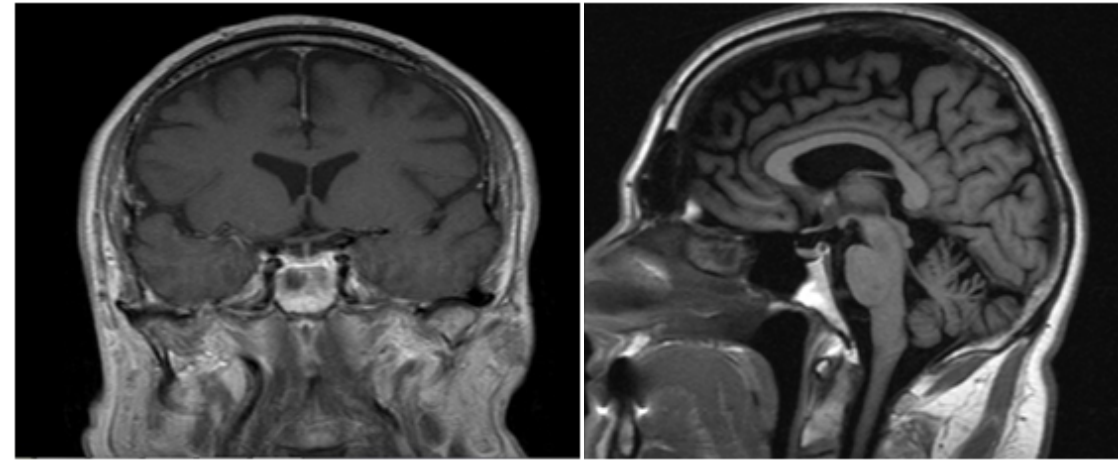

Axial T1 contrast MRI scan showing a normal pituitary gland and stalk before Ipilimumab

Saggital T1 contrast MRI scan showing a normal pituitary gland and stalk before Ipilimumab
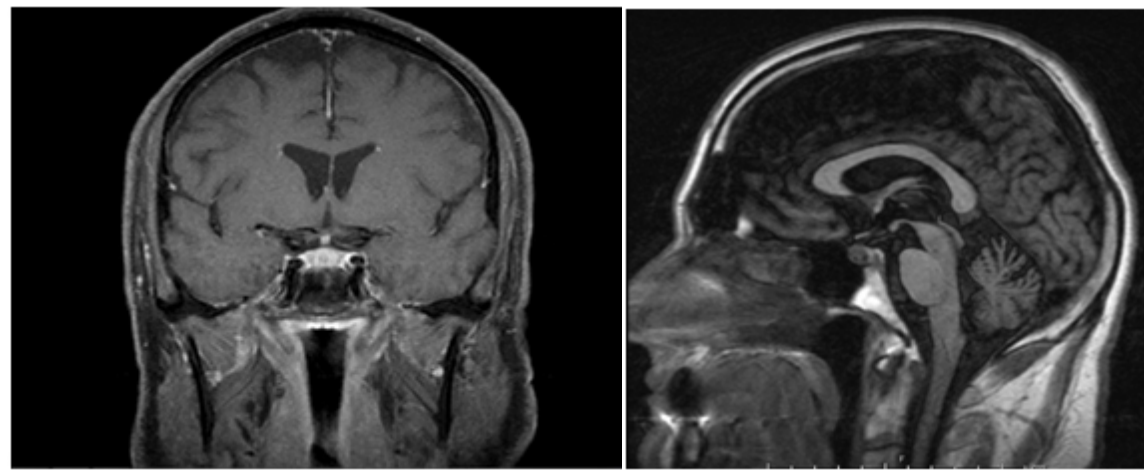

Post Ipilimumab T1 contrast MRI scan showing a $8.5 \mathrm{~mm}$ enlarged pituitary gland and stalk dimension of $3.1 \mathrm{~mm}$.

Post Ipilimumab T1 sagittal MRI scan showing a $8.5 \mathrm{~mm}$ enlarged pituitary gland.

\section{Discussion}

Lymphocytic/autoimmune hypophysitis is a rare inflammatory condition of the pituitary gland that causes multiple anterior hormonal deficiencies as well as symptoms due to mass effect. $^{1,2}$ Lymphocytic hypophysitis occurs more frequently in women compared to men (approximately $3: 1$ ratio of cases), ${ }^{3}$ in large part because of its association with pregnancy. ${ }^{4}$

Immunotherapy-associated hypophysitis occurs in up to $10-15 \%$ of patients receiving agents targeting cytotoxic T-lymphocyte-associated antigen 4 (CTLA-4), on average 2-3 months after starting therapy. ${ }^{5,6}$

Ipilimumab, a human monoclonal antibody (IgG1) that blocks cytotoxic Tlymphocyte-associated antigen 4 (CTLA-4) releases cytotoxic $T$ cells from the inhibitory effect of CTLA-4 and does stimulating anti-tumor immunity. ${ }^{7}$ Ipilimumab has shown improved recurrence-free survival for patients with completely resected high-risk stage III melanoma. ${ }^{6,8-10}$

The risk of developing hypophysitis in patients treated with ipilimumab has been reported to be as high as $13 \% .{ }^{6}$ Most patients were diagnosed with hypopituitarism after receiving $3 \mathrm{mg} / \mathrm{kg}$ ipilimumab and developed significant symptoms after a median time of 11 weeks, i.e. before the fourth dose, suggesting a possible cumulative effect. ${ }^{6}$

The cause of hypopituitarism is likely due to ipilimumab's immunomodulatory effect resulting activation of T-cells, leading to lymphocytic hypophysitis ${ }^{7,11-12}$ Iwama reported that CTLA-4 is expressed in pituitary endocrine cells and, when blocked by administration of a specific monoclonal antibody, this leads to site-specific deposition of complement components, pituitary infiltration and antibody formation. This study also showed that patients receiving ipilimumab develop pituitary antibodies. ${ }^{13}$ Hence, it remains uncertain whether the unfavorable effects are caused by T-cells acting against antigens shared by tumor cells and normal cells or from a direct antibody effect on CTLA-4 receptors on pituitary cells, or both.

In general patients with hypophysitis present with symptoms related to mass effect from 
pituitary gland enlargement and/or pituitary/hypothalamic dysfunction. ${ }^{11-14}$ Most patients present with headache, fatigue, asthenia, lethargy, nausea, loss of libido or (rarely) visual disturbances; only two patients have been described with visual field defects, which is explicable as pituitary enlargement is usually modest. ${ }^{14,15}$ Unlike other forms of hypophysitis, diabetes insipidus is extremely unusual in patients with immunotherapy-associated hypophysitis. ${ }^{5}$

In autoimmune hypophysitis induced by ipilimumab, Thyrotropin and Corticotrophin seem to be uniformly affected (100\%), usually confirmed by low TSH, FT4 levels, cortisol, and ACTH. ${ }^{12,14}$

$83-87 \%$ of male patients had hypogonadotrophic hypogonadism ${ }^{12,16}, 60 \%$ had IGF-1 deficiency. ${ }^{16}$ There is one reported case of Diabetes insipidus ${ }^{12}$ and one case of hyponatremia associated to SIADH. ${ }^{17}$ Serum prolactin can be low or high. ${ }^{14}$

MRI findings of the pituitary in patients with histologically confirmed lymphocytic hypophysitis usually show a uniformly enlarged and homogeneously enhancing gland, often with loss of posterior pituitary signal intensity on pre-contrast images and variable enlargement of the infundibular stalk. ${ }^{18}$ Similar changes are often seen in patients with ipilimumab - associated hypopituitarism but the magnitude seems to be reduced, and in some cases, the MRI has been regarded as within normal limits. ${ }^{16}$ If the pituitary enlarges, the height in sagittal dimension on MRI can go from 3.4-6 to $7.7-11.8 \mathrm{~mm} .{ }^{14}$ Follow up imaging, specially after 3 months, often demonstrates resolution of abnormal findings once hormonal replacement therapy has been initiated. ${ }^{18}$

The recommended treatment for Immune checkpoint inhibitors (ICPis) adverse affects like CTLA-4 inhibitors induced hypophysitis consists mostly of steroids and thyroid hormone replacement.

It is still unclear is high dose steroids are preferable to physiologic replacement in terms of outcome recovery of pituitary function.

Different trials have not shown any harmful effects of high-dose glucocorticoid therapy in cases of immune related adverse effects associated with ipilimumab antitumor responses, and the duration of tumor response does not seem to be affected by this treatment. ${ }^{11,14}$

Albare $^{19}$ and Blandsfield ${ }^{14}$ reported that high-dose glucocorticoids did not seem to modify the natural history of hypophysitis. Recovery of corticotroph function remains unlikely regardless of steroid dosage.

In this report, we suggest to screen patients with TSH, FT4, cortisol, ACTH and electrolyte levels before starting immunotherapy and we aim for a more physiologic dose of steroids because Lammert et al. ${ }^{20}$ have observed complications in five out of seven patients (four who needed to be hospitalized) after administration of high-dose corticosteroids for ipilimumabinduced hypophysitis, we suggest limiting the use of high dose steroids to patients with severe mass-effect related symptoms (headaches, visual defects) or severe hyponatremia. Puzanov et al. and the American Society of Clinical Oncology ${ }^{21,22}$ and National Comprehensive Cancer Network recommend to hold ICP is until patient is stabilized and start either prednisone 5-10 $\mathrm{mg}$ daily or hydrocortisone $10-20 \mathrm{mg}$ am and 5-10 $\mathrm{mg}$ in the early afternoon. The dose should be taper over 5-10 days and remember to start steroids few days before starting thyroid replacement.

If patients are going to be maintained on steroids, a proton pump inhibitor should be initiated for $\mathrm{Gl}$ prophylaxis and if immunosuppression is sustained for more than 3 weeks, PJP (pneumocystis jiroveci pneumonia) prophylaxis should be initiated. ${ }^{21}$

In patients that have developed symptomatic hypothyroidism, we recommend starting 1.6 $\mathrm{mg} / \mathrm{kg}$ of Levothyroxine in young/healthy patients. In patients with cardiovascular disease or in the elderly, we recommend starting a low dose like $25-50$ mcg of Levothyroxine a day. TSH and FT4 should be follow every 6-8 weeks after initiation of therapy and then periodically every 3 months during the first year and then every 6-12 months thereafter. Testosterone or estrogen should be replaced accordingly in patients without contraindications. GH replacement has not been reported. ${ }^{16}$ Mineralocorticoid replacement is not needed since the renin-angiotensin-aldosterone system remains intact.

The decision to continue CTLA4 antibody therapy should be made on the basis of a riskbenefit analysis by the oncologist and the endocrinologist taking into consideration the fact 
that hormone replacement therapy is relatively easy to administer.

There have been only three cases showing recovering of corticotroph function. ${ }^{12,23-25}$ Most patients remain on glucocorticoid replacement at 2-28 months at the time of reports. Pituitary-thyroid function recovered in $37-50 \%$ of patients. ${ }^{12,16}$ In the case series reported by Blansfield et al., ${ }^{14} 57 \%$ of men could discontinue testosterone replacement following normalization of the pituitary-gonadal axis.

\section{Conclusion}

Hypophysitis is a well-recognized side effect associated with CTLA4 antibodies. This case helps us to increase awareness of this condition. To date there are not specific guidelines that explain to physicians when to suspect about this disorder, however based on the evidence we suggest to screen patients before starting ICPis with TSH, FT4, electrolytes, cortisol and ACTH levels, we recommend asking for symptoms or signs of hypophysitis, adrenal insufficiency, hypothyroidismin every visit, specially between the third and fourth dose of CTLA4 antibodies. Corticosteroids are the main treatment and should be instituted as soon central adrenal insufficiency is diagnosed.

Now a day, endocrinologist should be aware of all the new immunotherapy used in cancer as they can cause severe endocrinopathies that can be life threatening if they are missed.

\section{References}

1. Caturegli P, Lupi I, Landek-Salgado M, Kimura H, Rose NR. Pituitary autoimmunity: 30 years later. Autoimmun Rev. 2008;7:631-637.

2. Beressi N, Beressi JP, Cohen R, Modigliani E. Lymphocytic hypophysitis. A review of 145 cases. Ann Med Interne (Paris). 1999;150:327-341.

3. Caturegli P, Newschaffer C, Olivi A, et al. Autoimmune hypophysitis. Endocr Rev. 2005;26:599-614.

4. Landek-Salgado MA, Gutenberg A, Lupi I, et al. Pregnancy, postpartum autoimmune thyroiditis, and autoimmune hypophysitis: intimate relationships. Autoimmun Rev. 2010;9:153-157.

5. Faje A. Immunotherapy and hypophysitis: clinical presentation, treatment, and biologic insights. Pituitary. 2016;19:82-92.

6. Hodi FS, O'Day SJ, McDermott DF, et al. Improved survival with ipilimumab in patients with metastatic melanoma. New England J Med. 2010; 363: 711-723.

7. O’Day SJ, Hamid O, Urba WJ. Targeting cytotoxic T-lymphocyte antigen-4 (CTLA-4): a novel strategy for the treatment of melanoma and other malignancies. Cancer. 2007;110:2614-2627.

8. Weber J, Thompson JA, Hamid O, et al. A randomized, double-blind, placebo-controlled, phase II study comparing the tolerability and efficacy of ipilimumab administered with or without prophylactic budesonide in patients with unresectable stage III or IV melanoma. Clin Cancer Res. 2009;15: 5591-5598.

9. O'Day SJ, Maio M, Chiarion-Sileni V, et al. Efficacy and safety of ipilimumab monotherapy in patients with previously treated, advanced melanoma: a multicenter, single-arm phase II study. Ann Oncol. 2010; 363: 711-723.

10. Robert C, Thomas L, Bondarenko I, et al. Ipilimumab plus dacarbazine for previously untreated metastatic melanoma. New England J Med. 2011; 364: 2517-2526.

11. Weber J. Review: anti-CTLA-4 antibody ipilimubab—case studies of clinical response and immunerelated adverse events. Oncologist. 2007; 12: 864-872.

12. Dillard T, Yedinak CG, Alumkal J, Fleseriu M. Anti-CTLA-4 antibody therapy associated autoimmune hypophysitis: serious immune related adverse events across a spectrum of cancer subtypes. Pituitary. 2010; 13: 29-38.

13. Iwama S, De Remigis A, Callahan MK, et al. Pituitary Expression of CTLA-4 Mediates Hypophysitis Secondary to Administration of CTLA-4 Blocking Antibody. Sci Transl Med. 2014; 6: 230ra45.

14. Blansfield JA, Beck KE, Tran K, et al. Cytotoxic T-lymphocyte-associated antigen-4 blockage can induce autoimmune hypophysitis in patients with metastatic melanoma and renal cancer. $J$ 
Immunotherapy. 2005; 28593-598.

15. Chodakiewitz Y, Brown S, Boxerman JL, Brody JM, Rogg JM. Ipilimumab treatment associated pituitary hypophysitis: Clinical presentation and imaging diagnosis. Clin Neurol Neurosurg. 2014; 125: $125-30$.

16. Min L, Vaidya A\& Becker C. Ipilimumab therapy for advanced melanoma is associated with secondary adrenal insufficiency: a case series. Endocrin Pract. 201: 11-13.

17. Barnard ZR, Walcott BP, Kahle KT, Nahed BV \& Coumans JV. Hyponatremia associated with ipilimumab-induced hypophysitis. Med Oncol. 2012; 29: 374-377.

18. Carpenter KJ, Murtagh RD, Lilienfeld H, Weber J \& Murtagh F. Ipilimumab-induced hypophysitis: MR imaging findings. AJNR. American J Neuroradiol. 2009; 30: 1751-1753.

19. Albarel F, Gaudy C, Castinetti F, et al. Long term follow up of ipilimumab-induced hypophysitis, a common adverse event of CTLA-4 antibody in melanoma. Eur J Endocrinol. 2015; 172:195-204.

20. Lammert A, Schneider HJ, Bergmann T, et al. Hypophysitis caused by ipilimumab in cancer patients: hormone replacement or immunosuppressive therapy. Exp Clin Endocrinol Diab. 2013; 121: 581-587.

21. Puzanov I, Diab A, Abdallah K, et al. Managing toxicities associated with immune checkpoint inhibitors: consensus recommendations from the Society for Immunotherapy of Cancer (SITC) Toxicity Management Working Group. J Immunother Cancer. 2017; 5:95.

22. Brahmer JR, Lacchetti C, Schneider BJ, et al. Thompson in collaboration with the National Comprehensive Cancer Network. Management of Immune- Related Adverse effects in patients treated with Immune Checkpoint Inhibitor Therapy: American Society of Clinical Oncology Clinical Practice Guideline. J Clin Oncol. 2010.

23. Downey SG, Klapper JA, Smith FO, et al. Prognostic factors related to clinical response in patients with metastatic melanoma treated by CTL-associated antigen-4 blockade. Clin Cancer Res. 2007; 13: 6681-6688.

24. Faje AT, Sullivan R, Lawrence D, et al. Ipilimumab-induced hypophysitis: a detailed longitudi- nal analysis in a large cohort of patients with metastatic melanoma. J Clin Endocrinol Metab. 2014; 59: 4078-4085.

25. Eggermont AM, Chiarion-Sileni V, Grob JJ, et al. Ipilimumab versus placebo after complete resection of stage III melanoma: Initial efficacy and safety results from the EORTC 18071 phase III trial. J Clin Oncol. 2014; 32:5s. 